\title{
Hubungan Pengetahuan dengan Sikap Tenaga Kesehatan dalam Tanggap Darurat Bencana Banjir di Puskesmas Bidara Cina Jakarta Timur
}

\author{
Adella Sari R, Fathinah Ranggauni H, Fandita Tonyka M, Arga Buntara dan Rafiah Maharani P
}

Program Studi Kesehatan Masyarakat, Universitas Pembangunan Nasional Veteran Jakarta, Indonesia

Email koresponden: fathinahranggaunihardy@gmail.com

Direvisi: 2020-02-13 Diterima: 2020-07-04

(C)2020 Fakultas Geografi UGM dan Ikatan Geograf Indonesia (IGI)

\begin{abstract}
Abstrak. Tanggap darurat adalah suatu tindakan yang dilakukan dengan secepat mungkin pada saat bencana terjadi untuk mencegah potensi buruk terhadap masyarakat. Dalam tanggap darurat bencana ini, dibutuhkan tenaga kesehatan yang memiliki pengetahuan dan pengalaman pelatihan terkait tanggap darurat bencana banjir. Tujuan penelitian ini adalah mengetahui hubungan pengetahuan dengan sikap tenaga kesehatan dalam tanggap darurat bencana banjir di Puskesmas Bidara Cina. Desain penelitian ini adalah cross-sectional dengan pendekatan kuantitatif dan kualitatif untuk mengetahui peran Puskesmas Bidara Cina 1, 2 dan 3. Sebanyak 32 tenaga kesehatan dilibatkan dalam penelitian ini dengan teknik total sampling. Pengumpulan data dilakukan dengan pengisian kuesioner oleh responden dan wawancara. Hasil penelitian menunjukkan terdapat hubungan yang bermakna antara pengetahuan dengan dengan sikap tenaga kesehatan dalam tanggap darurat bencana banjir $(\mathrm{p}=0,029)$. Bagi penelitian selanjutnya, disarankan untuk menambahkan simulasi tanggap darurat bencana banjir sebagai variabel tindakan tanggap darurat bencana.
\end{abstract}

Kata Kunci : Tenaga Kesehatan, Tanggap Darurat, Banjir

ABSTRACT. Emergency Response is an immediate action conducted when a disaster occurs to prevent any potential adverse impact on people. In emergency response, community health workers who have sufficient knowledge and training experience in flood disaster emergency response are required. The purpose of this research was to examine the relationship between knowledge and attitude of community health workers about flood disaster emergency response at Bidara Cina Primary Health Cares (PHC). The design of this research was a crosssectional design with quantitative and qualitative approaches to know the role of Bidara Cina 1, 2 and 3 Primary Health Cares in flood disaster emergency response. A total of 32 community health workers were recruited in this research by using total sampling technic. Data collection was conducted by questionnaires filling and interviews. The result shows that there was a significant relationship between knowledge and attitude of community health workers about flood disaster emergency response $(p=0,029)$. Further studies which use a flood disaster emergency response simulation as an additional variable are recommended.

Keywords: Community Health Workers, Emergency Response, Flood

\section{PENDAHULUAN}

Banjir menurut Bakornas ialah fenomena alam yang terjadi pada musim hujan yang dapat mengancam kehidupan masyarakat sehingga menyebabkan timbulnya korban jiwa, dampak psikologis, kerugian harta benda, serta kerusakan lingkungan (BAKORNAS PB, 2007). Kejadian banjir dipengaruhi oleh faktor curah hujan yang melebihi batas normal dan adanya pasang surut air laut. Ulah manusia seperti penggunaan lahan yang tidak sesuai lokasi (permukiman di daerah bantaran sungai, di daerah resapan, penggundulan hutan), pembuangan sampah ke dalam sungai, pembangunan permukiman di daerah dataran banjir ialah faktor lain yang menyebabkan banjir. Namun, pada umumnya $80 \%$ bencana terjadi dikarenakan adanya perubahan iklim (Climate Change) (Ika, 2013).

Bencana banjir merupakan bencana yang terbesar di dunia. Data Guidelines for Reducing Flood Losses, United Nations - International Strategy for Disaster Reduction
(UN-ISDR) menyatakan bahwa jumlah kejadian bencana banjir di dunia dari tahun 1975-2001 semakin meningkat, 20 kejadian pada tahun 1975 meningkat pesat menjadi 147 kejadian, pada tahun 2001 dengan jumlah kematian paling tinggi pada tahun 1999 ialah sebanyak \pm 35.000 jiwa (UNISDR, 2001). Bencana banjir melanda negara-negara di dunia seperti yang menyerang daerah Pyongyang di negara Korea Selatan. Banjir di daerah tersebut mengakibatkan ribuan orang meninggal atau hilang dan lebih dari 30.000 rumah penduduk hancur termasuk bangunan pemukiman, jembatan, dan jalur kereta api juga mengalami kerusakan (BBC NEWS, 2007).

Indonesia ialah negara yang mempunyai banyak daerah yang rawan akan bencana alam. Hal ini dikarenakan terbukti dengan Indeks Rawan Bencana (IRB) yang dikeluarkan oleh Badan Nasional Penanggulangan Bencana (BNPB) yang menunjukkan bahwa 27 provinsi di Indonesia mempunyai 
IRB tinggi dan 6 provinsi berindeks sedang (BNPB, 2016). Data bencana banjir pada tahun 2015 di Indonesia terjadi sebanyak 504 kali (BNPB, 2016).

Daerah rawan banjir yang tertinggi di Indonesia salah satunya adalah DKI Jakarta. Menurut Kajian Risiko Bencana DKI Jakarta Tahun 2016-2002 Kejadian-kejadian bencana yang pernah terjadi di Provinsi DKI Jakarta memperlihatkan bahwa upaya penanggulangan bencana masih kurang efektif. Hal ini terlihat dari kejadian bencana 10 tahun terakhir (tahun 2006-2015) yang tercatat pada Data dan Informasi Bencana (BNPB, 2015). Kejadian bencana banjir merupakan kejadian yang paling sering terjadi di Provinsi DKI Jakarta yaitu 75 kali kejadian serta yang paling banyak menimbulkan dampak korban jiwa, kerusakan infrastruktur dan lingkungan/lahan yang tidak sedikit (BNPB, 2015).

Dampak kesehatan yang terjadi dikarenakan tenaga kesehatan tidak memberikan pelayanan kesehatan pada saat terjadi bencana terutama bencana banjir dapat menimbulkan dampak yang lebih buruk apabila korban tidak segera ditangani seperti memperparah potensi kejadian luar biasa (KLB) atau penyakit yang ditularkan melalui media air (water -borne diseases) seperti diare, leptospirosis, dan penyakitpenyakit lainnya yang diakibatkan bencana banjir (Departemen Kesehatan RI, 2001).

Berdasarkan Kajian Risiko Bencana Kota Administrasi Jakarta Timur Tahun 2013-2017, masih rendahnya pengetahuan masyarakat tentang banjir baik dari segi kesiapsiagaan bencana banjir, tanggap darurat bencana banjir, dan lain-lain dengan melihat indeks $\mathrm{PB}$ (Pengetahuan Bencana) berada pada level rendah (BNPB, 2017).

Berdasarkan penelitian (Fakhrurrazi, Mulyadi dan Ismail, 2015) menyatakan bahwa sebanyak 12 tenaga kesehatan (66,7\%) yang mempunyai pengetahuan yang baik dan siap menghadapi risiko bencana banjir. Hasil uji statistik diperoleh nilai p. Value yaitu 0,011 ( $p<0,05$. Lalu, sebanyak 12 tenaga kesehatan $(70,6 \%)$ mempunyai sikap yang baik dan siap menghadapi risiko bencana banjir. Hasil uji statistik diperoleh nilai p. Value yaitu 0,004 ( $\mathrm{p}<$ $0,05)$. Variabel kesiapsiagaan terdapat sebanyak 16 orang tenaga kesehatan atau $(53,3 \%)$ yang tidak siap dalam menghadapi risiko bencana banjir.

Penelitian yang dilakukan oleh Husna (2011) menyatakan bahwa kesiapsiagaan bencana di Instalasi Gawat Darurat Rumah Sakit Umum Daerah dr. Zainoel Abidin Banda Aceh berada pada kategori baik yang berjumlah 25 orang $(83,3 \%)$ dan pengetahuan terhadap risiko bencana di instalasi gawat darurat Rumah Sakit Umum Daerah dr. Zainoel Abidin Banda Aceh berada pada kategori baik yaitu sebanyak 19 orang $(63,3 \%)$.

Berdasarkan pada studi pendahuluan yang dilakukan peneliti dengan metode observasi, lokasi Puskesmas Bidara Cina 1, 2 dan 3 ini terletak dekat dengan bantaran kali ciliwung yang berpotensi terjadinya banjir akibat luapan air sungai. Penelitian ini dilakukan di 3 Puskesmas di wilayah Jakarta Timur yaitu Puskesmas Bidara Cina 1, Puskesmas Bidara Cina 2, dan Puskesmas Bidara Cina 3 dengan pertimbangan bahwa lokasi Puskesmas Bidara Cina ini merupakan wilayah yang terdekat dengan bantaran kali dan pernah terjadi bencana banjir pada tahun 2014, 2017, dan 2018 setinggi \pm 1 meter dan menyebabkan kerusakan infrastruktur serta terjadinya kelumpuhan pada pelayanan kesehatan.

Berdasarkan wawancara yang dilakukan dengan
Kepala Puskesmas Bidara Cina 1, 2 dan 3, bahwa tingkat pengetahuan pada tenaga kesehatan masih dikatakan kurang dikarenakan beberapa tenaga kesehatan belum pernah mengikuti pelatihan terkait tanggap darurat bencana banjir. Puskesmas Bidara Cina juga tidak memiliki program dan SOP mengenai penanganan banjir terhadap masyarakat yang terkena dampak bencana banjir. Mereka hanya menyelamatkan data-data mengenai pasien dan infrastruktur yang ada di puskesmas. Selain itu, tidak adanya koordinasi langsung antara puskesmas dengan BPBD sehingga mereka tidak mendapatkan sosialisasi mengenai tanggap darurat bencana khususnya bencana banjir dalam pelayanan kesehatan.

Berdasarkan pada latar belakang penelitian, penulis ingin melakukan penelitian dengan judul "Hubungan Pengetahuan dengan Sikap Tenaga Kesehatan Dalam Tanggap Darurat Bencana Banjir di Puskesmas Bidara Cina Jakarta Timur Tahun 2019.”

\section{METODE PENELITAIAN}

Berdasarkan tujuan, penelitian ini merupakan penelitian kuantitatif dengan jenis survey analitik dan penelitian kualitatif untuk memperkaya informasi dengan mengetahui peran puskesmas dalam tanggap darurat bencana banjir serta menggunakan metode cross sectional. Alasan menggunakan metode ini cross sectional karena mudah sesuai dengan tujuan penelitian yaitu untuk untuk melihat tingkat pengetahuan tenaga kesehatan dalam tanggap darurat bencana, tidak diperlukan follow-up lebih lanjut serta diukur secara bersamaan dalam satu waktu.

Penelitian ini dilakukan di Puskesmas Bidara Cina 1, Puskesmas Bidara Cina 2, dan Puskesmas Bidara Cina 3, Jakarta Timur. Penelitian ini dilakukan pada bulan Mei sampai Juni 2019. Penelitian ini terdiri dari uji validitas kepada tenaga kesehatan, penyebaran kuesioner dan wawancara yang termasuk data primer. Sedangkan data sekunder berupa data bencana banjir yang diperoleh dari BPBD DKI Jakarta dan data-data profil mengenai Puskesmas Bidara Cina 1, 2 dan 3. Populasi dalam penelitian ini adalah seluruh tenaga kesehatan yang berjumlah 32 orang dengan teknik total sampling. Alasan menggunakan total sampling dilakukan karena populasi yang kurang dari 100 .

Adapun variabel penelitian yang digunakan dalam penelitian ini diantaranya variabel bebas yaitu pengetahuan tenaga kesehatan dalam tanggap darurat bencana banjir. Teknik pengambilan data primer dalam penelitian ini dilakukan melalui penyebaran kuesioner dan wawancara dengan tujuan untuk memudahkan peneliti mendapatkan data tentang pengetahuan tenaga kesehatan, sikap tenaga kesehatan dan peran puskesmas dalam tanggap darurat bencana banjir. Sedangkan data sekunder diperoleh berupa data bencana banjir yang diperoleh dari BPBD DKI Jakarta, data-data profil mengenai Puskesmas Bidara Cina 1, 2 dan 3. Data yang didapatkan akan dianalisis univariat untuk mengetahui distribusi frekuensi setiap variabel dan analisis bivariat menggunakan uji Chi-Square untuk mengetahui hubungan antar variabel bebas dengan variabel terikat serta analisis kualitatif untuk mengetahui peran puskemas dalam tanggap darurat bencana banjir.

\section{HASIL DAN PEMBAHASAN}

Hasil penelitian ini terdiri dari hasil univariat, hasil bivariat, dan hasil analisis kualitatif. Hasil univariat didapatkan 
distribusi frekuensi berupa karakteristik responden (usia, pendidikan, jenis tenaga kesehatan, pengalaman pelatihan tanggap darurat bencana) serta pengetahuan dan sikap tenaga kesehatan. Distribusi frekuensi dari variabel bebas dan variabel terikat dapat dilihat pada tabel berikut.

\section{Analisis Univariat}

Karakteristik Responden (Usia, Pendidikan, Jenis Tenaga Kesehatan, Pengalaman Pelatihan Tanggap Darurat Bencana) serta Pengetahuan dan Sikap Tenaga Kesehatan

Dari tabel 1 dapat diketahui bahwa karakteristik responden dari usia tua sebanyak 16 dari 32 tenaga kesehatan (50\%), sedangkan responden usia muda sebanyak 16 dari 32 tenaga kesehatan (50\%). Karakteristik responden dari tenaga kesehatan yang berpendidikan Diploma III (D3) yaitu 22 dari 32 tenaga kesehatan (69\%), sedangkan tenaga kesehatan yang berpendidikan Strata I (S1) yaitu 10 dari 32 tenaga kesehatan (31\%). Karakteristik responden dari tenaga kesehatan paramedis berjumlah 21 dari 32 tenaga kesehatan (66\%), sedangkan tenaga kesehatan nonparamedis berjumlah 11 dari 32 tenaga kesehatan (34\%). Karakteristik responden dari tenaga kesehatan yang pernah mengikuti pelatihan tanggap darurat bencana yaitu 15 dari 32 tenaga kesehatan (47\%), sedangkan tenaga kesehatan yang tidak pernah mengikuti pelatihan tanggap darurat bencana yaitu 17 dari 32 tenaga kesehatan (53\%).

Variabel pengetahuan dapat dilihat bahwa responden dengan pengetahuan baik sebanyak 18 dari 32 tenaga kesehatan (56\%), responden berpengetahuan cukup sebanyak 14 dari 32 tenaga kesehatan (44\%). Variabel sikap didapatkan bahwa sikap responden yang memiliki sikap positif sebesar 15 dari 32 tenaga kesehatan (47\%), sedangkan 17 dari 32 tenaga kesehatan (53\%) memiliki sikap negatif.

Tabel 1. Distribusi Frekuensi karakteristik responden (usia, pendidikan, jenis tenaga kesehatan, pengalaman pelatihan tanggap darurat bencana), serta pengetahuan dan sikap tenaga kesehatan

\begin{tabular}{|c|c|c|}
\hline Variabel & $\mathrm{N}$ & $\%$ \\
\hline \multicolumn{3}{|l|}{ Usia } \\
\hline Usia Tua (> Median 30,00) & 16 & 50 \\
\hline Usia Muda ( $\leq$ Median 30,00$)$ & 16 & 50 \\
\hline \multicolumn{3}{|l|}{ Pendidikan } \\
\hline Diploma III (D3) & 22 & 69 \\
\hline Strata I (S1) & 10 & 31 \\
\hline \multicolumn{3}{|l|}{ Jenis Tenaga Kesehatan } \\
\hline Paramedis & 21 & 66 \\
\hline Nonparamedis & 11 & 34 \\
\hline \multicolumn{3}{|c|}{$\begin{array}{l}\text { Pengalaman Pelatihan Tanggap Da- } \\
\text { rurat Bencana }\end{array}$} \\
\hline Pernah & 15 & 47 \\
\hline Tidak Pernah & 17 & 53 \\
\hline \multicolumn{3}{|l|}{ Pengetahuan } \\
\hline Baik & 18 & 56 \\
\hline Cukup & 14 & 44 \\
\hline \multicolumn{3}{|l|}{ Sikap } \\
\hline Positif & 15 & 47 \\
\hline Negatif & 17 & 53 \\
\hline Total & 32 & 100 \\
\hline
\end{tabular}

Analisis Bivariat

Hubungan Pengetahuan dengan Sikap Tenaga Kesehatan Dalam Tanggap Darurat Bencana Banjir

Hasil analisis bivariat menyebutkan bahwa pengetahuan yang baik dengan sikap yang positif berjumlah 12 dari 32 tenaga kesehatan (67\%), sedangkan sikap yang negatif berjumlah 6 dari 32 tenaga kesehatan (33\%). Pengetahuan yang cukup dengan sikap yang positif berjumlah 3 dari 32 tenaga kesehatan (21\%), sedangkan sikap yang negatif berjumlah 11 dari 32 tenaga kesehatan (79\%). Hasil penelitian ini berdasarkan uji chi-square, menunjukkan bahwa terdapat hubungan yang signifikan antara pengetahuan dengan sikap tenaga kesehatan karena nilai p-value 0,029 kurang dari 0,05.

\section{Analisis Kualitatif}

Peran Puskesmas Dalam Tanggap Darurat Bencana Banjir di Puskesmas Bidara Cina

\section{Koordinasi}

Dalam indikator pertanyaan mengenai koordinasi puskesmas kepada BPBD sesuai dengan Surat Keputusan (SK) Menteri Kesehatan No. 145/Menkes/SK/112007 tentang Pedoman Penanggulangan Bencana Bidang Kesehatan, Kepala Puskesmas Bidara Cina 1 menyatakan bahwa koordinasi yang dilakukan secara berjenjang mulai dari Puskesmas Kecamatan Jatinegara, Suku Dinas Kesehatan, dan Dinas Kesehatan serta tidak koordinasi langsung dengan BPBD.

Kepala Puskesmas Bidara Cina 2 menyatakan bahwa Puskesmas Bidara Cina 2 tidak koordinasi langsung dengan BPBD, tetapi berkoordinasi langsung dengan Kantor Kelurahan Bidara Cina dan Puskesmas Kecamatan Jatinegara dan koordinasi dilakukan secara bertingkat.

Kepala Puskesmas Bidara Cina 3 menyatakan bahwa koordinasi kepada BPBD tidak secara langsung tetapi dengan memantau ketinggian air melalui aplikasi BPBD. Koordinasi yang bertingkat dari BPBD ke Kelurahan Bidara Cina.

\section{Kunjungan Dinas Kesehatan/Suku Dinas Kesehatan}

Berdasarkan indikator pertanyaan mengenai kunjungan Dinas Kesehatan atau Suku Dinas Kesehatan Jakarta Timur sesuai dengan Surat Keputusan (SK) Menteri Kesehatan No. 145/Menkes/SK/112007 tentang Pedoman Penanggulangan Bencana Bidang Kesehatan, Kepala Puskesmas Bidara Cina 1 menyatakan bahwa hanya Suku Dinas Kesehatan serta Puskesmas Kecamatan Jatinegara yang memantau untuk melihat situasi apakah terkena banjir atau tidak serta apakah ada penyakit yang muncul akibat bencana banjir. Tetapi, mereka tidak sering datang dikarenakan Puskesmas Bidara Cina 1 jarang terkena banjir dan mereka lebih sering turun langsung ke lokasi bencana banjir atau posko banjir yang diadakan Kelurahan Bidara Cina.

Kepala Puskesmas Bidara Cina 2 menyatakan bahwa hanya Sudinkes yang berkunjung ke Puskesmas Bidara Cina 2 untuk meninjau lokasi Puskesmas Bidara Cina 2 untuk melihat bangunan gedung puskesmas karena Puskesmas Bidara Cina 2 memiliki gedung yang baru dikarenakan puskesmas sering mengalami banjir sedangkan Dinas Kesehatan tidak pernah berkunjung ke Puskesmas Bidara Cina 2.

Kepala Puskesmas Bidara Cina 3 menyatakan bahwa pada saat penanggulangan bencana banjir, Puskesmas Kecamatan Jatinegara yang datang terlebih dahulu ke lokasi. Puskesmas kecamatan ini membantu dalam pendirian posko banjir di 
kantor kelurahan. Pendirian posko banjir berdasarkan pada ketinggian sama luas dari banjir dan seberapa parah banjir itu datang. Apabila banjir tidak terlalu parah, biasanya pendirian posko banjir di kantor kelurahan saja, tetapi kalau banjir sudah parah pendirian posko banjir di Gor Otista. Tergantung dari intensitasnya.

\section{Staf Penanggulangan Bencana Banjir}

Berdasarkan indikator pertanyaan mengenai staf penanggulangan bencana banjir sesuai dengan Surat Keputusan (SK) Menteri Kesehatan No. 145/Menkes/SK/112007 tentang Pedoman Penanggulangan Bencana Bidang Kesehatan, Kepala Puskesmas Bidara Cina 1 menyatakan bahwa tidak ada staf penanggulangan bencana yang khusus tetapi ada satu orang sanitarian yang bertanggung jawab ikut andil langsung dalam bencana banjir. Tetapi, di Puskesmas Bidara Cina 1 jarang terjadi banjir sehingga tenaga kesehatan turun langsung membantu korban banjir terutama di sekitar Puskesmas Bidara Cina 3. Tenaga kesehatan yang ikut andil langsung yaitu semua tenaga kesehatan Puskesmas Bidara Cina 1 terutama dokter, perawat, dan tenaga kefarmasian.

Kepala Puskesmas Bidara Cina 2 menyatakan bahwa terdapat tim gawat darurat Puskesmas Kecamatan Jatinegara tetapi pada Puskesmas Bidara Cina 2 ini tidak memiliki tim gawat darurat. Puskesmas Jatinegara menugaskan kepada staf-staf seluruh Puskesmas Kelurahan Bidara Cina untuk bertugas pada saat bencana banjir serta dibuat jadwal piket untuk pembagian tugas dalam kejadian bencana banjir.

Kepala Puskesmas Bidara Cina 3 menyatakan bahwa pegawai laki-laki di Puskesmas Bidara Cina 3 ini yang menjadi tim gawat darurat bencana banjir. Mereka selalu standby dan mendapat informasi melalui grup whatsapp apabila banjir datang.

\section{Struktur Kesehatan Lingkungan}

Berdasarkan indikator pertanyaan mengenai struktur kesehatan lingkungan menurut Kementrian Kesehatan RI dalam Pedoman Teknis Penanggulangan Krisis Kesehatan Akibat Bencana tahun 2011, Kepala Puskesmas Bidara Cina 1 menyatakan bahwa terdapat satu orang tenaga kesehatan lingkungan yang bertanggung jawab dalam bencana banjir dan tempat kerjanya di Puskesmas Bidara Cina 1. Tetapi, bukan banjir saja yang menjadi fokus tenaga kesehatan lingkungan, tetapi mengurus yang lainnya seperti limbah puskesmas.

Kepala Puskesmas Bidara Cina 2 menyatakan bahwa terdapat tenaga kesehatan lingkungan sebanyak satu orang di Puskesmas Bidara Cina 1,2 dan 3 tetapi posisi tenaga kesehatan lingkungan tersebut berada di Puskesmas Bidara Cina 1. Tenaga kesehatan lingkungan tersebut ikut berperan tetapi perannya tidak secara langsung dikarenakan tenaga kesehatan lingkungan bukan hanya menangani bencana banjir saja tetapi banyak tugas-tugas lainnya. Tugas tenaga kesehatan lingkungan berfokus pada air limbah puskesmas serta kasus DBD baik DBD diakibatkan bencana banjir maupun tidak.

Kepala Puskesmas Bidara Cina 3 menyatakan bahwa tenaga kesehatan lingkungan di Puskesmas Bidara Cina memegang 16 RW dan tenaga kesehatan lingkungan itu standby di Puskesmas Bidara Cina 1 dan pada saat banjir datang tenaga kesehatan lingkungan ikut andil. Sehabis banjir, tenaga kesehatan lingkungan mengadakan lisolisasi atau pembersihan lingkungan sekitar yang terkena banjir.
Alokasi Khusus

Berdasarkan indikator pertanyaan mengenai alokasi khusus menurut Kementrian Kesehatan RI dalam Pedoman Teknis Penanggulangan Krisis Kesehatan Akibat Bencana tahun 2011 bahwa terdapat alokasi khusus berupa obat dan perbekalan alat kesehatan. Kepala Puskesmas Bidara Cina 1 menyatakan bahwa alokasi khusus pada saat bencana banjir adalah obat-obatan. Obat-obatan yang dibutuhkan yaitu obat yang dibutuhkan oleh korban banjir. Kelurahan Bidara Cina menyumbang konsumsi, selimut, baju layak pakai, pembalut, dan lain-lain bagi korban banjir yang biasanya terjadi pada daerah sekitar Puskesmas Bidara Cina 2 dan Puskesmas Bidara Cina 3.

Kepala Puskesmas Bidara Cina 2 menyatakan bahwa alokasi khusus pada saat bencana banjir tidak berupa uang, tapi berupa obat-obatan. Selama obat-obatan di Puskesmas Bidara Cina 2 cukup, mereka tidak meminta obat-obatan tambahan.

Kepala Puskesmas Bidara Cina 3 menyatakan bahwa alokasi khusus hanya obat-obatan saja. Pihak kelurahan memberikan konsumsi, selimut, baju bekas, dan lain-lain.

\section{Dampak Kesehatan}

Berdasarkan indikator pertanyaan mengenai dampak kesehatan akibat bencana banjir menurut Kementrian Kesehatan RI dalam Buku Penanggulangan Pusat Krisis Kesehatan tahun 2016 bahwa terdapat beberapa penyakit yang timbul dikarenakan bencana banjir yaitu seperti penyakit diare, leptospirosis, DBD, penyakit kulit, dan penyakitpenyakit lainnya yang disebabkan karena bencana banjir. Kepala Puskesmas Bidara Cina 1 menyatakan bahwa penyakit yang timbul hanya penyakit yang umum seperti diare, penyakit kulit, demam, batuk, pilek, dan tidak pernah terjadi KLB pada saat bencana banjir.

Kepala Puskesmas Bidara Cina 2 menyatakan bahwa penyakit yang timbul pada saat bencana banjir yaitu seperti penyakit kulit, ISPA, diare dan tidak pernah terjadi KLB atau sakit karena KLB.

Kepala Puskesmas Bidara Cina 3 menyatakan bahwa KLB yang terjadi berupa penyakit batuk, pilek, demam, penyakit kulit. Kalau penyakit DBD timbul pada saat $\mathrm{H}+1$ bulan setelah bencana banjir datang.

\section{Lokasi Puskesmas}

Berdasarkan indikator pertanyaan mengenai lokasi puskesmas yang tidak strategis dan letaknya di dekat bantaran kali sesuai dengan Peraturan Menteri Kesehatan Republik Indonesia Nomor 75 Tahun 2014 Tentang Pusat Kesehatan Masyarakat bahwa lokasi puskesmas harus memenuhi persyaratan dengan letak geografis yang strategis, terdapat aksesibilitas bagi jalur transportasi, dan lain-lain. Kepala Puskesmas Bidara Cina 1 menyatakan bahwa lokasi Puskesmas Bidara Cina 1 tidak terlalu dekat dengan bantaran kali ciliwung daripada Puskesmas Bidara Cina 3 yang dekat dengan bantaran kali. Mereka tidak mengetahui kenapa Puskesmas Bidara Cina 1 dibangun hampir dekat dengan bantaran kali dikarenakan puskesmas ini didirikan pada tahun 1970an dan mereka juga belum mengetahui bahwa terdapat undang-undang yang mengatur persyaratan lokasi puskesmas.

Kepala Puskesmas Bidara Cina 2 menyatakan bahwa Puskesmas Bidara Cina 2 berdiri pada tahun 1974. Kepala Puskesmas Bidara Cina 2 tidak mengetahui bahwa pem- 
bangunan Puskesmas Bidara Cina 1, 2 dan 3 berada di dekat bantaran kali ciliwung. Letak Puskesmas Bidara Cina 1 lebih bagus daripada letak Puskesmas Bidara Cina 3 yang terletak di tempat terpencil dan tidak strategis.

Kepala Puskesmas Bidara Cina 3 menyatakan bahwa Puskesmas Bidara Cina 3 ini berdiri sejak tahun 1975 dan tidak mengetahui kenapa puskesmas ini didirikan di sekitar bantaran kali dikarenakan pada zaman dahulu mungkin tidak ada lahan yang kosong sehingga membangun puskesmas di dekat bantaran kali.

\section{PEMBAHASAN}

Analisis Hubungan Pengetahuan dengan Sikap Tenaga Kesehatan Dalam Tanggap Darurat Bencana Banjir

Berdasarkan hasil penelitian, didapatkan bahwa 18 dari 32 tenaga kesehatan yang berpengetahuan baik, terdapat sebanyak 12 dari 32 tenaga kesehatan $(67 \%)$ yang memiliki sikap positif dalam tanggap darurat bencana banjir dan 6 dari 32 tenaga kesehatan (33\%) yang memiliki sikap negatif dalam tanggap darurat bencana banjir, sedangkan dari 14 dari 32 tenaga kesehatan yang berpengetahuan cukup, terdapat 3 dari 32 tenaga kesehatan (21\%) yang memiliki sikap positif dalam tanggap darurat bencana banjir dan 11 dari 32 tenaga kesehatan (79\%) yang memiliki sikap negatif dalam tanggap darurat bencana banjir. Hasil uji statistik diperoleh $p$ -value sebesar 0,029 ( $\mathrm{p}<0,05)$, ini berarti Ho ditolak dan Ha diterima sehingga kesimpulannnya yaitu ada hubungan yang signifikan antara pengetahuan tenaga kesehatan dengan sikap dalam tanggap darurat bencana banjir di Puskesmas Bidara Cina. Hasil penelitian menunjukkan bahwa tingkat pengetahuan secara kognitif tenaga kesehatan di Puskesmas Bidara Cina tentang tanggap darurat menghadapi bencana lebih banyak pada kategori baik yaitu sebanyak 18 dari 32 tenaga kesehatan. Menurut Notoatmodjo (2010) pengetahuan yaitu domain yang sangat penting untuk terbentuk suatu perilaku. Setelah seseorang mengetahui dan melakukan pengindraan terhadap suatu obyek hal tersebut menghasilkan sebuah pengetahuan. Pengindraan ini terjadi melalui mata, telinga, hidung, lidah dan kulit. Tetapi sebagian besar pengetahuan manusia diperoleh melalui mata dan telinga. Penelitian ini sejalan dengan penelitian Fakhrurrazi, Mulyadi, dan Ismail tahun 2015 yang berjudul "Pengetahuan Dan Sikap Tenaga Kesehatan Rumah Sakit Umum Daerah (Rsud) Pidie Jaya Terhadap Kesiapsiagaan Dalam Menghadapi Risiko Bencana Banjir" menjelaskan bahwa ada hubungan antara pengetahuan dengan kesiapsiagaan tenaga kesehatan. Hasil penelitian menunjukkan bahwa p-value sebesar 0,011 maka dikatakan sangat signifikan, karena p kurang dari 0,05.

Berbeda dengan penelitian (Sari, 2015) yang berjudul "Hubungan pengetahuan perawat instalasi gawat darurat (IRD) dengan kesiapan menghadapi bencana di RSUD Majene" menjelaskan bahwa hasil penelitian dengan menggunakan uji statistik Fisher Exact diperoleh p-value $(\rho=0,166>\alpha=0,05)$. Dengan demikian H1 ditolak yang berarti tidak terdapat hubungan pengetahuan perawat IRD terhadap kesiapan menghadapi bencana di RSUD Majene tahun 2015.

Pengetahuan baik yang dimiliki tenaga kesehatan dalam menghadapi bencana banjir yaitu seperti pengetahuan kebencanaan, manajemen bencana, tanggap darurat bencana, triase, dan lain-lain yang terdapat dalam Pedoman Teknis Penanggulangan Krisis Kesehatan Akibat
Bencana (Kementrian Kesehatan RI, 2011).

Pengetahuan yang baik tidak terlepas dari berbagai informasi yang pernah dibaca, didengar, ataupun ditonton oleh tenaga kesehatan sebab kemampuan menjawab pertanyaan sangat berhubungan dengan kemudahan informasi yang didapatkan. Hasil penelitian ini sesuai dengan Yava dkk. (2013) yang menyatakan bahwa tenaga kesehatan yang membaca buku-buku, jurnal, dan yang memperoleh informasi dari media massa dan elektronik sehingga memiliki skor pengetahuan lebih tinggi daripada mereka yang tidak memperoleh informasi dari media massa atau elektronik.

Hal ini juga hampir sama dengan penelitian yang dilakukan oleh Dewi (2013) dalam Fakhrurrazi, Mulyadi dan Ismail (2015) menyatakan bahwa kesiapsiagaan menghadapi bencana banjir mengharuskan tenaga kesehatan agar mempunyai pengetahuan yang luas dan dituntut agar dapat menggunakan kemampuan dalam berbagai aspek kehidupan. Dapat disimpulkan bahwa pengetahuan yang baik dapat membuat seseorang mempunyai pengetahuan yang luas tentang bencana sehingga membuat tenaga kesehatan lebih siaga dalam menghadapi serta mengurangi bencana banjir.

Sikap terhadap tanggap darurat bencana banjir dikatagorikan cukup baik karena tenaga kesehatan telah didasari oleh pengetahuan terhadap risiko bencana yang baik sehingga menumbuhkan sikap yang baik pula terhadap tanggap darurat bencana. Hal ini di dukung oleh pendapat Mubarak (2012) sikap merupakan kecenderungan terhadap suatu stimulus atau objek yang berdampak pada bagaimana seseorang berhadapan dengan objek atau stimulus tersebut. Ini berarti sikap menunjukan kesetujuan atau ketidaksetujuan, suka atau tidak suka seseorang terhadap objek. Sikap dalam kehidupan sehari-hari ialah reaksi yang bersifat emosional terhadap stimulus sosial.

Hasil penelitian ini juga sesuai dengan teori yang dikemukakan Soenaryo (2004) dalam Pratiwi (2014) menyatakan bahwa pengetahuan ialah objek yang penting untuk membentuk suatu sikap. Sikap yang didasari pengetahuan umumnya bersifat tetap, yaitu apabila seseorang yang memiliki pengetahuan yang baik paling tidak telah mengetahui suatu masalah dan dapat menganalisanya sehingga melakukan tindakan yang lebih baik dari seseorang yang memiliki pengetahuan kurang. Penelitian ini hampir sama dengan penelitian Fakhrurrazi (2015) menyatakan bahwa bahwa dari 30 responden, terdapat 12 tenaga kesehatan $(70,6 \%)$ yang mempunyai sikap yang baik dan siap menghadapi risiko bencana banjir. Hasil uji statistik diperoleh p-value yaitu 0,004 ( $<<0,05)$, sehingga dapat disimpulkan bahwa terdapat hubungan yang signifikan antara sikap tenaga kesehatan dengan kesiapsiagaan menghadapi risiko bencana banjir di Rumah Sakit Umum Daerah Pidie Jaya. Dalam penelitian Pratiwi (2014) menyebutkan bahwa pada hasil penelitiannya terdapat $\mathrm{p}$-value sebesar 0,000 ( $\mathrm{p}<0,05)$. Hal ini menyatakan bahwa terdapat hubungan yang signifikan antara pengetahuan terhadap sikap kesiapsiagaan bencana pada tenaga kesehatan Puskesmas Banda Aceh.

Sikap tenaga kesehatan yang telah didasari dengan pengetahuan tanggap darurat dapat melakukan tindakan dengan menerapkan tanggap darurat pada saat bencana banjir yaitu sesuai dengan Peraturan Kepala Badan Nasional Penanggulangan Bencana (2008) bahwa tanggap darurat 
merupakan tindakan yang dilakukan dengan secepat mungkin pada saat terjadinya bencana untuk menangani dampak buruk yang akan terjadi. Tindakan tersebut terdiri dari evakuasi dan penyelamatan korban, harta benda, pemenuhan kebutuhan dasar korban pengungsi, perlindungan dan pengurusan korban pengungsi, dan pemulihan sarana dan prasarana (Undang-Undang Republik Indonesia Nomor 24 Tahun 2007).

Puskesmas juga mempunyai peran dalam menanggulangi bencana banjir yang terjadi. Menurut Surat Keputusan (SK) Menteri Kesehatan No. 145/Menkes/SK/112007 tentang Pedoman Penanggulangan Bencana Bidang Kesehatan bahwa peran puskesmas dalam menanggulangi bencana banjir pada saat terjadinya bencana yaitu peran puskesmas di lokasi bencana : menuju lokasi bencana dengan membawa peralatan yang diperlukan untuk melaksanakan triase, memberikan pertolongan pertama pada korban, melaporkan kejadian bencana kepada Kepala Dinas Kesehatan (Kadinkes) Kabupaten/Kota, melakukan penilaian cepat masalah kesehatan awal (initial rapid health assessment), serta menyerahkan tanggung jawab kepada Kadinkes Kabupaten/ Kota bila telah tiba di lokasi. Peran puskesmas di sekitar lokasi bencana : mengirimkan tenaga dan perbekalan kesehatan serta ambulans/transportasi lain ke lokasi bencana dan tempat penampungan pengungsi, membantu perawatan, evakuasi korban, serta pelayanan kesehatan pengungsi (Departemen Kesehatan, 2007).

\section{KESIMPULAN}

Karakteristik responden dari usia tua sebanyak 16 dari 32 tenaga kesehatan (50\%), sedangkan responden usia muda sebanyak 16 dari 32 tenaga kesehatan (50\%). Karakteristik responden dari tenaga kesehatan yang berpendidikan Diploma III (D3) sebanyak 22 dari 32 tenaga kesehatan (69\%), sedangkan tenaga kesehatan yang berpendidikan Strata I (S1) sebanyak 10 dari 32 tenaga kesehatan $(31 \%)$. Karakteristik responden dari tenaga kesehatan paramedis berjumlah 21 dari 32 tenaga kesehatan (66\%), sedangkan tenaga kesehatan nonparamedis berjumlah 11 dari 32 tenaga kesehatan (34\%). Karakteristik responden dari tenaga kesehatan yang pernah mengikuti pelatihan tanggap darurat bencana yaitu 15 dari 32 tenaga kesehatan (47\%), sedangkan tenaga kesehatan yang tidak pernah mengikuti pelatihan tanggap darurat bencana yaitu 17 dari 32 tenaga kesehatan (53\%).

Pengetahuan dan sikap tenaga kesehatan dalam tanggap darurat bencana banjir di Puskesmas Bidara Cina 1, 2, dan 3 cukup baik. Hasil penelitian diketahui bahwa ada hubungan antara pengetahuan dengan sikap tenaga kesehatan dalam tanggap darurat bencana banjir dengan $p$ value $0,029<0,05$.

\section{DAFTAR PUSTAKA}

Badan Koordinasi Nasional Penanggulangan Bencana (BAKORNAS PB).(2007). Pedoman Penanggulangan Bencana Banjir, Bakornas Pb. Jakarta: Pelaksana Harian BAKORNAS PB.

Badan Nasional Penanggulangan Bencana.(2015).Kajian Risiko Bencana DKI Jakarta 2016 - 2020. Jakarta.

Badan Nasional Penanggulangan Bencana. (2017).Dokumen Kajian Risiko Bencana Kota Administrasi Jakarta Timur Tahun 2013-2017. Jakarta. doi: 10.21580/wa.v3i1.868.

Badan Nasional Penanggulangan Bencana (BNPB).(2016). Risiko Bencana Indonesia (Disasters Risk of Indonesia), Direktorat
Pengurangan Resiko Bencana Deputi Bidang Pencegahan dan Kesiapansiagaan. Jakarta.

BBC NEWS. BBC NEWS.(2007).Asia-Pacific. "Hundreds dead" in N Korea floods. Korea. (cited: 21 February 2019). Available at:http://news.bbc.co.uk/2/hi/asiapacific/6945315.stm.

BNPB. (2013). Data Bencana Indonesia 2013, Katalog BPS. Jakarta. (cited: 5 March 2019). Available at:

https://www.bps.go.id/website/pdf_publikasi/Statistik-Indonesia2017.pdf.

BNPB. (2019). Data Bencana, Jakarta. 2016. (cited: 6 March 2019). Available at: bnpb.go.id/data-bencana/lihat-data.

Departemen Kesehatan. (2007). Keputusan Menteri Kesehatan Republik Indonesia Nomor 145/MENKES/SK/I/2007 Tentang Pedoman Penanggulangan Bencana Bidang Kesehatan. Jakarta.

Departemen Kesehatan RI.(2001). Pedoman Penanggulangan Masalah Kesehatan Akibat Kedaruratan Kompleks, Penangulangan Kesehatan. Jakarta.

Fakhrurrazi, Mulyadi dan Ismail, N. (2015).'Pengetahuan Dan Sikap Tenaga Kesehatan Rumah Sakit Umum Daerah (Rsud) Pidie Jaya Terhadap Kesiapsiagaan Dalam Menghadapi Risiko Bencana Banjir', Jurnal Ilmu Kebencanaan: Program Pascasarjana Unsyiah, Vol 2, No 4: November 2015, pp. 112. [skripsi]. (cited: 20 April 2019). Available at: http:// www.jurnal.unsyiah.ac.id/JIKA/article/view/8152.

Husna, C.(2011) 'Faktor-Faktor yang Mempengaruhi Kesiapsiagaan Bencana di RSUDZA Banda Aceh'. [skripsi]. (cited: 25 June 2019). Banda Aceh: Universitas Syiah Kuala; 2011. Available at: viewFile/1578/1459.

http://www.jurnal.unsyiah.ac.id/INJ/article/

Ika. (2013).'Universitas Gadjah Mada: 80 Persen Bencana di Indonesia Akibat Perubahan Iklim’. cited: 21 February 2019). Available at: https://ugm.ac.id/id/ berita/849680.persen.bencana.di.indonesia.akibat.perubaha n.iklim.

Kemenkes RI. (2016).'Sudah Siapkah Kita Menghadapi Banjir?', Buku Penanggulangan Pusat Krisis Kesehatan. Jakarta.

Kementrian Kesehatan RI. (2011).Pedoman Teknis Penanggulangan Krisis Kesehatan Akibat Bencana. Jakarta; 2011.

Mubarak, W. I.(2012). Promosi Kesehatan untuk Kebidanan. Jakarta: Salemba Medika.

Notoatmodjo, S. (2010). Promosi Kesehatan dan Perilaku Kesehatan. Jakarta: Rineka Cipta; 2010.

Peraturan Kepala Badan Nasional Penanggulangan Bencana.(2008) Pedoman Penyusunan Rencana Penanggulangan Bencana, Pedoman Penyusunan Rencana Penanggulangan Bencana. Jakarta.

Pratiwi, R. A. N. (2014). Hubungan Pengetahuan Dengan Sikap Kesiapsiagaan Bencana Pada Tenaga Kesehatan Puskesmas Banda Aceh. [skripsi]. (cited: 26 June 2019). Banda Aceh: Universitas Syiah Kuala.

Sari, W.(2015). 'Hubungan Pengetahuan Perawat Instalasi Gawat Darurat ( IRD ) Dengan Kesiapan Menghadapi Bencana Di RSUD Majene', 1(2), pp. 146-153. [skripsi]. Sulawesi Barat: Universitas Sulawesi Barat.

Undang-Undang Republik Indonesia Nomor 24 Tahun 2007, Undang-Undang Republik Indonesia Nomor 24 Tahun 2007 tentang Penanggulangan Bencana. Jakarta.

UNISDR (2001) Guidelines for Reducing Flood Losses, United Nations. (cited: 23 February 2019). Available at: http:// www.unisdr.org/eng/library/isdr-publication/floodguidelines/Guidelines-for-reducing-floods-losses.pdf.

Yava, A. et al.(2013). 'Knowledge and attitudes of nurses about pain management in Turkey', International Journal of Carling Sciences, 6(3), pp. 496-505.(cited: 26 June 2019). Available at: http://www.internationaljournalofcaringsciences.org/ docs/23. Yava.pdf. 